\title{
Glycemic control amongst diabetic subjects on insulin therapy: Still off target!
}

\author{
Bhujanga Shetty S. ${ }^{1}{ }^{*}$, Ramachandrappa L. ${ }^{2}$ \\ DOI: https://doi.org/10.17511/ijmrr.2019.i04.05 \\ 1* Surekha Bhujanga Shetty, Assistant Professor, Karnataka Institute of Endocrinology and Research, Bangalore, Karnataka, India. \\ 2 Lalitha Ramachandrappa, Assistant Professor, Karnataka Institute of Endocrinology and Research, Bangalore, Karnataka, India.
}

Introduction: Prevalence of diabetes is increasing worldwide. Good glycemic control is essential for prevention of complications of diabetes. Despite of availability of multiple medications, it is difficult to achieve good glycemic control. Insulin therapy is considered to be the best option available for attaining glycemic control. But, whether insulin therapy has achieved it is an important question to be addressed. Objective: To assess the glycemic control in subjects with diabetes on insulin therapy. Materials and Methods: A cross-sectional study was done at Karnataka Institute of Endocrinology and research, Bangalore, in 448 diabetic patients who were on insulin therapy as a part of their diabetic therapy. Data collected was analyzed using SPSS 22 version software. Results: Majority of the subjects were men (61.38\%) and in the age group of $>60$ years (44.9\%). Many of the subjects on insulin therapy had duration of diabetes $>5$ years, with $36.4 \%$ having duration of 10-20 years, while another $36 \%$ had duration of $5-10$ years. Premixed insulin ( $81.47 \%)$ was the most commonly used insulin regimen. $82.6 \%$ of the subjects were on conventional insulin and only $13.2 \%$ were on insulin analogues. Insulin syringe was the most commonly used delivery device, with $64.7 \%$ of subjects using it, while insulin pen was used by $33.5 \%$ subjects. Despite of insulin therapy, the glycemic control was poor and $81.4 \%$ had $\mathrm{HbA} 1 \mathrm{C}>8 \%$. Only $5.7 \%$ of the subjects had $\mathrm{HbA} 1 \mathrm{C}$ $<7 \%$. $94.9 \%$ of the subjects reported that they were regular with their insulin therapy. Only $20.1 \%$ adjusted the insulin dose by self. Conclusions: The present study has found that despite being on insulin therapy, large percentage of subjects was unable to achieve good glycemic control.

Keywords: Diabetes Mellitus, Insulin

Corresponding Author

Surekha Bhujanga Shetty, Assistant Professor, Karnataka Institute of Endocrinology and Research, Bangalore, Karnataka, India.

Email: doc.surekha@gmail.com
How to Cite this Article

To Browse

Shetty SB, Ramachandrappa L. Glycemic control amongst diabetic subjects on insulin therapy: Still off target!. Int J Med Res Rev. 2019;7(4):280-286. Available From

https://ijmrr.medresearch.in/index.php/ijmrr/article/ view/1070

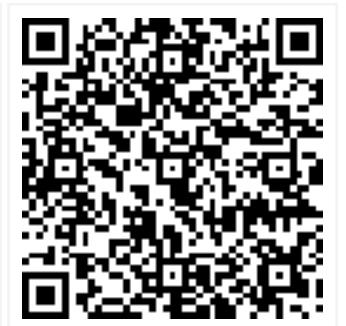

Manuscript Received 2019-06-04

Conflict of Interest No
Review Round 1 2019-06-14

Funding $\mathrm{Nil}$

Review Round 2
2019-06-20
$\begin{gathered}\text { Ethical Approval } \\ \text { Yes }\end{gathered}$

Review Round 2

Yes
Review Round 3

Plagiarism X-checker $8 \%$
Accepted 2019-06-23

Note

(C) 2019 by Surekha Bhujanga Shetty, Lalitha Ramachandrappa and Published by Siddharth Health Research and Social Welfare Society. This is an Open Access article licensed under a Creative Commons Attribution 4.0 International License https://creativecommons.org/licenses/by/4.0/ unported [CC BY 4.0]. 


\section{Introduction}

Type 2 diabetes mellitus is one of the most common chronic diseases worldwide. According to the current statistics, 425 million adults (1-in-11) have diabetes. Unfortunately, Diabetes is associated with high morbidity and mortality rate, having caused 4 million deaths in 2017 [1]. Due to the gradually increasing burden of diabetes, it has been recognized as one of the four priority noncommunicable diseases targeted for action by the United Nations. It has been emphasised that early and aggressive management of diabetes is essential for risk reduction of diabetes related mortality and morbidity [2]. To achieve glycemic control, there are several classes of anti diabetic drugs available with different mechanism of action, efficacy and safety profile. Due to the slowly progressive beta-cell failure, most subjects with type 2 diabetes will require stepwise intensification of anti-diabetic therapy to maintain good glycemic control. Yet, only small percentage of subjects can maintain the goal with oral anti-diabetic drugs and over a period of time, large percentage of subjects will need addition of insulin therapy to attain an $\mathrm{HbA} 1 \mathrm{c}$ level below $7 \%$ [3].

Being discovered in 1921, insulin is the oldest of the anti-diabetic medications available and hence has the most clinical experience. It is also the most effective agent in lowering blood glucose levels, when used in appropriate doses. In addition, unlike oral anti-diabetic drugs, there is no maximum dose of insulin beyond which therapeutic effect will not occur [4]. Despite of these advantages, it is observed that large percentage of subjects on insulin therapy have elevated HbA1c levels and experience years of uncontrolled hyperglycemia. This is attributable to several obstacles in implementing appropriate insulin therapy. Multiple patient and physician factors have been found to create barriers in achieving optimal glycemic control with insulin therapy. Concerns regarding injections, hypoglycaemia, weight gain and lifestyle restrictions are few reasons for delay in initiating and maintaining insulin therapy. Patient acceptance, willingness to comply with the therapy, use of appropriate regimen and dose titration also contribute to the treatment outcomes [5]. But, the data on glycemic control with insulin therapy is scarce. It is essential to analyse whether glycemic control with insulin therapy is achievable or not, so as to plan a strategy for optimising insulin therapy.
This study therefore aimed at assessing the glycemic control status in subjects with type 2 diabetes on insulin therapy, in the outpatient department of Karnataka Institute of Endocrinology and Research, Bangalore.

Objectives: To assess the level of glycemic control in subjects on insulin therapy.

\section{Materials and Methods}

Study design: A cross-sectional observational study was conducted in the outpatient department of Karnataka Institute of Endocrinology and research, Bangalore. 448 diabetic subjects who were on insulin therapy as a part of their diabetic therapy, of any age, and with diabetes of any duration were recruited for the study, between January to August 2015.

\section{Inclusion criteria}

01. Diabetic patients of any age and duration of diabetes.

02. On insulin therapy for at least 6 months duration.

\section{Exclusion criteria}

01 . Subjects unwilling to participate in the study.

02. Pregnant women.

Ethical approval: The study was approved by the ethical committee of the hospital. The patients consent to participate in the study was taken, after the nature of the study was explained to them.

Data collection procedures: A questionnaire based interview of 448 diabetic patients who were self administering insulin as a part of their diabetic therapy was conducted. The questionnaire incorporated data on gender, age, occupation, educational status, duration of diabetes, duration of insulin use, type of insulin regimen, insulin delivery device used and drug compliance. Glycemic control was assessed by noting the current HbA1C.

Statistical analysis: Data was entered into Microsoft excel data sheet and was analyzed using SPSS 22 version software. Categorical data was represented in the form of frequencies and proportions. Chi-square was used as the test of significance. Independent $t$ test was used as the test of significance for quantitative data. Continuous data was represented as mean and standard deviation. $P$ value $<0.05$ was considered as statistically significant. 


\section{Results}

In the study, $95.5 \%$ of subjects were type 2 diabetics and $4.5 \%$ had type 1 diabetes. Mean age of the subjects in the study was $55 \pm 10.78$ years. Mean age of type 1 diabetes subjects was $15.95 \pm 10.78$ years and type 2 diabetes subjects was $56.82 \pm 11.66$ years. Majority of subjects were in the age group of $>60$ years $(44.9 \%)$. $30.8 \%$ of the subjects were in the age group of 50-59 years. $10.7 \%$ subjects were in the age group of $40-49$ years. $13.6 \%$ of the subjects were less than 39 years. $61.38 \%$ of the subjects were male and $38.62 \%$ of the subjects were females. $36.4 \%$ had duration of diabetes between 10 to 20 years; $25.7 \%$ had duration between 5 to 10 years, $15.2 \%$ had duration between 1 to 5 years, $12.3 \%$ had duration $>20$ years and $10.5 \%$ had duration <1 year. $34.8 \%$ of the subjects were using insulin for $<1$ year, $33.9 \%$ between 1 to 5 years and $31.3 \%$ of subjects had duration of insulin use $>5$ years. $14.1 \%$ of the subjects had education up to primary school, $27.5 \%$ had education up to high school, and $12.7 \%$ had studied up to pre-university / diploma, $23.7 \%$ were graduates and $22.1 \%$ were illiterate. $99.8 \%$ of subjects in the study were right handed and $17.9 \%$ of subjects had abnormal vision (Table 1 ). Regarding the type of insulin used, $8.04 \%$ of the subjects were using basal insulin, $8.48 \%$ were using bolus insulin, $81.47 \%$ were using premixed insulin and $6.03 \%$ were using basal-bolus insulin. $82.6 \%$ of the subjects were using conventional insulin, $13.2 \%$ were using analogue insulin and $4.2 \%$ were using combination of conventional and analogue insulin. With respect to the insulin device used, $64.7 \%$ of the subjects were using insulin syringe, 33.5\% were using insulin pen and $1.8 \%$ were using both (Table 2).

Table-1: Baseline characteristics.

\begin{tabular}{|l|l|l|l|}
\hline \multicolumn{2}{|c|}{ Characteristic } & \multicolumn{1}{|c|}{ Frequency } & Percent \\
\hline \multirow{3}{*}{ Type of DM } & Type 1 & 20 & 4.5 \\
\cline { 2 - 4 } & Type 2 & 428 & 95.5 \\
\hline \multirow{4}{*}{ Age } & $<39$ years & 61 & 13.6 \\
\cline { 2 - 4 } & 40 to 49 years & 48 & 10.7 \\
\cline { 2 - 4 } & 50 to 59 years & 138 & 30.8 \\
\cline { 2 - 4 } & $>60$ years & 201 & 44.9 \\
\hline \multirow{2}{*}{ Mean age (Mean \pm SD $)$} & $55 \pm 14.36$ years \\
\hline \multirow{2}{*}{ Mean age type 1 DM $(n=20)$} & $15.95 \pm 10.78$ years \\
\hline Mean age type 2 DM $(n=428)$ & $56.82 \pm 11.66$ years \\
\hline \multirow{2}{*}{ Gender } & Male & 275 & 61.38 \\
\cline { 2 - 4 } & Female & 173 & 38.62 \\
\hline
\end{tabular}

\begin{tabular}{|l|l|l|l|}
\hline Duration of diabetes & $<1$ year & 47 & 10.5 \\
\cline { 2 - 4 } & 1 to 5 year & 68 & 15.2 \\
\cline { 2 - 4 } & 5 to 10 year & 115 & 25.7 \\
\hline & 10 to 20 year & 163 & 36.4 \\
\cline { 2 - 4 } & $>20$ years & 55 & 12.3 \\
\hline Education & Illiterate & 99 & 22.1 \\
\cline { 2 - 5 } & Primary school & 63 & 14.1 \\
\hline High school & 123 & 27.5 \\
\hline & PUC and diploma & 57 & 12.7 \\
\cline { 2 - 5 } & Graduate and above & 106 & 23.7 \\
\hline
\end{tabular}

Table-2: Insulin regimen used.

\begin{tabular}{|c|c|c|c|c|c|c|}
\hline \multirow{3}{*}{$\begin{array}{l}\text { Duration of insulin } \\
\text { use }\end{array}$} & $<1$ year & \multicolumn{3}{|c|}{156} & \multicolumn{2}{|c|}{34.8} \\
\hline & 1 to 5 years & \multicolumn{3}{|c|}{152} & \multicolumn{2}{|c|}{33.9} \\
\hline & $>5$ years & \multicolumn{3}{|c|}{140} & \multicolumn{2}{|c|}{31.3} \\
\hline \multirow[t]{4}{*}{ Insulin regime used } & Basal only & \multicolumn{3}{|l|}{36} & \multicolumn{2}{|c|}{8.04} \\
\hline & Bolus only & \multicolumn{3}{|l|}{38} & \multicolumn{2}{|c|}{8.48} \\
\hline & Pre mixed & \multicolumn{3}{|c|}{365} & \multicolumn{2}{|c|}{81.47} \\
\hline & Basal-bolus & \multicolumn{3}{|l|}{27} & \multicolumn{2}{|c|}{6.03} \\
\hline \multirow[t]{3}{*}{ Type of insulin used } & Conventional & \multicolumn{3}{|c|}{370} & \multicolumn{2}{|c|}{82.6} \\
\hline & Analogue & \multicolumn{3}{|l|}{59} & \multicolumn{2}{|c|}{13.2} \\
\hline & $\begin{array}{l}\text { Conventional + } \\
\text { analogue }\end{array}$ & \multicolumn{3}{|l|}{19} & \multicolumn{2}{|c|}{4.2} \\
\hline \multirow[t]{4}{*}{ Insulin device used } & Insulin syringe & \multirow[t]{2}{*}{$\begin{array}{l}29 \\
8\end{array}$} & \multirow[t]{2}{*}{64.7} & $40 \mathrm{IU}$ & 29 & 97.3 \\
\hline & & & & $100 I U$ & 8 & 2.7 \\
\hline & Insulin pen & \multirow{2}{*}{15} & \multirow[t]{2}{*}{33.5} & Refillable & 99 & 62.6 \\
\hline & & & & Disposable & & 37.4 \\
\hline
\end{tabular}

Table-3: Glycemic Levels in subjects on insulin therapy.

\begin{tabular}{|l|l|l|l|}
\hline & \multicolumn{1}{|c|}{ Levels } & \multicolumn{1}{c|}{ Number } & \multicolumn{1}{c|}{ Percentage } \\
\hline HbA1c $(n-366)$ & $<7$ & 21 & 5.7 \\
\cline { 2 - 4 } & 7 to 8 & 47 & 12.8 \\
\cline { 2 - 4 } & $>8$ & 298 & 81.4 \\
\hline
\end{tabular}

Table-4: Practices among diabetic subjects with respect to insulin injection technique.

\begin{tabular}{|l|l|l|l|l|l|l|}
\hline \multicolumn{2}{|c|}{ Parameter } & \multicolumn{2}{c|}{ Yes } & \multicolumn{2}{c|}{ No } & \multirow{2}{*}{ Total } \\
\cline { 2 - 7 } & Count & $\%$ & Count & $\%$ & \\
\hline 1 & Take insulin injections regularly & 425 & 94.9 & 23 & 5.1 & 448 \\
\hline 2 & Adjust the dose of insulin by self & 88 & 20.1 & 351 & 79.9 & 439 \\
\hline
\end{tabular}

Mean HbA1c of subjects in the study was 9.91 1.97 . Among type 1 diabetics, mean HbA1c was $10.85 \pm 2.76$ and among type 2 diabetic mean $\mathrm{HbA1c}$ was $9.86 \pm 1.91$. This difference in mean HbA1c between Type 1 and Type 2 DM subjects was statistically significant. $81.45 \%$ of the subjects had $\mathrm{HbA} 1 \mathrm{c}>8$, while $12.8 \%$ had $\mathrm{HbA} 1 \mathrm{c}$ between 7-8. Only $5.7 \%$ of the subjects had $\mathrm{HbA} 1 \mathrm{c}<7$ (Table 3 ). $94.9 \%$ were taking insulin regularly. Only $20.1 \%$ adjusted the insulin dose by self (Table 4). 


\section{Discussion}

Diabetes is said to be uncontrolled when the blood glucose levels/glycosylated hemoglobin levels are not within the targets specified for that particular patient at a given time. HbA1c $<7.0 \%$, pre-prandial capillary plasma glucose of $80-130 \mathrm{mg} / \mathrm{dl}$ and peak postprandial capillary plasma glucose $<180 \mathrm{mg} / \mathrm{dl}$ are considered as the glycemic targets for nonpregnant adults with diabetes by ADA recommendations [6]. Despite of the increasing therapeutic options for management of diabetes, inability to achieve good glycemic control remains the greatest challenge for the medical fraternity.

Several subsequently mentioned studies have documented high prevalence of uncontrolled diabetes. NHANES data from 1999-2002 showed that only $49.8 \%$ of the studied population had HbA1C $<7 \%$. On the basis of the survey, it was concluded that considerable proportion of U.S adults with diabetes did not achieve ADA recommendations [7].

The situation hasn't changed much over time. In a single-center, cross-sectional study of 452 type 2 diabetes subjects, conducted in Pakistan in 2003, prevalence of uncontrolled diabetes (HbA1c $\geq 8 \%$ ) was found to be $38.9 \%$ [8]. A hospital-based crosssectional survey in Ghana found that $86.4 \%$ of diabetics could not control their blood glucose level [9]. In a cross-sectional survey done in 2008-2010 among 12,077 Spanish individuals, about $71 \%$ had HbA1C $<7 \%$, 22\% had blood pressure $<130 / 80$ $\mathrm{mmHg}$, and $36 \%$ reached the LDL-cholesterol goal of $<100 \mathrm{mg} / \mathrm{dl}$.

Though the scenario appears better than other countries, the authors concluded that even in a country with universal healthcare coverage, glycemic control among aware diabetic individuals was poor and suggested a need for improvement in both clinical guidelines' implementation and patients' adherence [10]. Studies from India also show poor glycemic control amongst subjects with diabetes.

The Diab Care-Asia-India 1998 study $(n=2269)$ showed poor glycaemic control in over $50 \%$ of the study population. The mean HbA1c was $8.9 \pm 2.1 \%$ in this study [11]. More than a decade after this survey, DiabCare India 2011 study $(n=6168)$ also found that glycaemic control is sub-optimal in type 2 diabetes patients with a mean $\mathrm{HbA1C}$ of $8.9 \pm 2.1 \%$.
It showed that only $19.7 \%$ of subjects with type 2 diabetes have good glycemic control in India [12]. A cross-sectional, retrospective analysis of 206 diabetic subjects in Mathura, Uttar Pradesh in 2018 showed a mean HbA1C of $9.1 \pm 11.6 \%$. HbA1c level above $7 \%$ was found in $65 \%$ of cases. Age, duration of diabetes, drug utilization patterns and BMI were the significant factors impacting glycemic control [13].

Studies suggest that insulin therapy also has failed in achieving good glycemic control. In Diab Care India 2011 study, subjects on insulin, either alone or in combination constituted $41.8 \%$ of the study population [11]. In the Mathura study done in 2018, $23.8 \%$ of the subjects were on insulin therapy and $91.8 \%$ of these had poor glycemic control [13]. In another study of 423 type 2 diabetes subjects in Saudi Arabia, "poor glycemic control" defined by fasting blood glucose $>130 \mathrm{mg} / \mathrm{dL}$ was seen in $74.9 \%$ of the subjects. Here, $78.3 \%$ of subjects on insulin therapy had poor diabetes control, while $73.2 \%$ subjects on oral drugs had poor glycemic control [14].

A Cross-sectional study of 5750 subjects with diabetes, in 14 centres in Brazil, mean HbA1c was $8.6 \pm 2.2 \%$. HbA1c $<7 \%$ was observed in only $26 \%$ of patients. Patients with $\mathrm{HbA} 1 \mathrm{c} \geq 8 \%$ were younger, non-whites, had longer diabetes duration, more sedentary, and treated more frequently with insulin than patients with HbA1c $<8 \%$ [15]. In a crosssectional study in 1111 adults with type 2 diabetes attending diabetes centres in Saudi Arabia, mean HbA1c was $8.5 \pm 1.9 \%$.

About three-fourths of participants had inadequate glycaemic control $(\geq 7 \%)$. Multivariable analysis showed that age $\leq 60$ years, longer duration of diabetes, low household income, low intake of fruits and vegetable, low level of physical activity, high waist-hip ratio, low adherence to medication, and using injectable medications were independent risk factors for inadequate glycaemic control [16].

Among 480 subjects with self-reported diabetes in Phase I of INDIAB (2008 -2010), good glycemic control ( $\mathrm{HbA} 1 \mathrm{c}<7 \%$ ) was observed only in $31.1 \%$ of urban and $30.8 \%$ of rural subjects. Younger age, duration of diabetes, insulin use, and high triglyceride levels were significantly associated with poor glycemic control. Insulin use was associated with poor glycemic control with odds ratio of 2.479 (95\% CI, 1.012-6.072; $\mathrm{P}=0.047$ ) [17]. 
In the current study, mean was $\mathrm{HbA} 1 \mathrm{c}$ was $9.91 \pm 1.97$, which is almost 2 points above the ADA targets. Less than $6 \%$ had $\mathrm{HbA} 1 \mathrm{C}<7$, which denotes very poor performance with regards to diabetes control.

In the present study population, it was noted that premixed insulin was the most commonly used insulin regimen, conventional insulin was the commonest insulin used and insulin syringe was the commonest device used. It appears that use of multi-dose insulin regimen, insulin analogues, and pen devices could have helped in achieving better glycemic control.

Self titration of insulin dose was not done frequently by our subjects. This highlights the need for patients on insulin therapy to be educated on self titration of insulin dose, so as to achieve rapid glycemic control. In summary, use of better insulin regimens, frequent blood glucose monitoring and insulin dose modification might help better glycemic control.

There are few limitations of the present study. First, being a tertiary referral center, subjects with uncontrolled diabetes could be visiting this center, thus giving rise to selection bias. Second, since the study was cross-sectional, it doesn't provide information about temporal or causal association. It would have been interesting to analyse the causes for poor glycaemic control in these subjects including the disease factors, patient factors and treatment factors that led to inadequate control even with insulin therapy.

\section{Conclusions}

The present study has found that despite being on insulin therapy, large percentage of subjects had poor glycemic control. The study confirms the need for frequent counselling, re-evaluation and modification of factors responsible for persistent hyperglycemia. It ascertains the need to acknowledge that just initiating insulin therapy will not reduce hyperglycemia, but frequent monitoring and titration of insulin regimen is necessary for achieving optimal success with insulin therapy.

The study highlights the need to increase awareness among patients and healthcare providers regarding the importance of good glycemic control, so that decisions on treatment intensification can be taken and implemented at the appropriate time to protect patients from poor glycemic memory.
The study highlights that patients be empowered to effectively use insulin with the help of team-based aggressive glycemic management process and improve patient outcomes.

\section{Contribution of the study to the existing knowledge}

This study is one of the few studies performed to determine the glycemic control among insulin treated diabetic subjects. The main strength of the study is that it is a large survey. The study demonstrates that even with insulin therapy, large percentage of subjects have uncontrolled diabetes. It highlights that unless right insulin regimen and dose titration is used, insulin therapy will not lead to good glycemic control.

\section{Author's contribution}

Dr. Surekha Bhujanga Shetty: Concept, collection of study data, data compilation/ analysis and manuscript preparation.

Dr. Lalitha Ramachandrappa: Collection of study data, data compilation/ analysis and manuscript preparation.

\section{Abbreviations}

01. ADA: American Diabetes Association

02. HbA1c: Glycosylated Hemoglobin

03. IDF: International Diabetes Federation

04. NHANES: National Health and Nutrition Examination Survey

\section{Reference}

01. Federation ID. IDF Diabetes Atlas Eighth Edition. 2017.

[Crossref]

02. World Health Organization. Global action plan for the prevention and control of noncommunicable diseases 2013-2020.

[Crossref]

03. Turner RC, Cull CA, Frighi V, Holman RR. Glycemic control with diet, sulfonylurea, metformin, or insulin in patients with type 2 diabetes mellitus: progressive requirement for multiple therapies (UKPDS 49), UK Prospective Diabetes Study (UKPDS) Group. JAMA. 1999;281(21)2005-12.

DOI: $\quad 10.1001 /$ jama.281.21.2005 [Crossref] 
04. Nathan DM, Buse JB, Davidson MB, Ferrannini E, Holman RR, Sherwin $R$, et al. Medical management of hyperglycemia in type 2 diabetes- a consensus algorithm for the initiation and adjustment of therapy- a consensus statement of the American Diabetes Association and the European Association for the Study of Diabetes. Diab Care. 2009;32(1)193-203.

DOI: $10.2337 / \mathrm{dc0}-9025$ [Crossref]

05. Peyrot M, Rubin RR, Khunti K. Addressing barriers to initiation of insulin in patients with type 2 diabetes. Prim Care Diabetes. 2010;4(1)S11-8.

DOI: $10.1016 / \mathrm{S} 1751-9918(10) 60004-6$ [Crossref]

06. American Diabetes Association. 6 Glycemic Targets- Standards of Medical Care in Diabetes2019. Diab Care. 2019;42(1)S61-S70.

DOI: $10.2337 / \mathrm{dc} 19-\mathrm{S} 006$ [Crossref]

07. Resnick HE, Foster GL, Bardsley J, Ratner RE. Achievement of American Diabetes Association clinical practice recommendations among US adults with diabetes, 1999-2002- the National Health and Nutrition Examination Survey. Diab Care. $2006 ; 29(3) 531-7$.

DOI: $10.2337 /$ diacare.29.03.06.dc05-1254 [Crossref]

08. Siddiqui FJ, Avan BI, Mahmud S, Nanan DJ, Jabbar A, Assam PN. Uncontrolled diabetes mellitus: prevalence and risk factors among people with type 2 diabetes mellitus in an Urban District of Karachi, Pakistan. Diab Res Clin Pract. 2015;107(1)148-56.

DOI: $10.1016 /$ j.diabres.2014.09.025 [Crossref]

09. Fiagbe J, Bosoka S, Opong J, Takramah W, Axame WK, Owusu R, et al. Prevalence of controlled and uncontrolled diabetes mellitus and associated factors of controlled diabetes among diabetic adults in the hohoe municipality of Ghana. Diab Manage. 2017;7(5)343-54.

[Crossref]

10. Navarro-Vidal B, Banegas JR, León-Muñoz LM, Rodríguez-Artalejo F, Graciani A. Achievement of cardiometabolic goals among diabetic patients in Spain- A nationwide population-based study. PLoS One. 2013;8(4)e61549.

DOI: $10.1371 /$ journal.pone.0061549 [Crossref]
11. Raheja BS, Kapur A, Bhoraskar A, Sathe SR, Jorgensen LN, Moorthi SR, et al. DiabCare AsiaIndia Study- diabetes care in India-current status. J Assoc Physicians India. 2001;49;71722.

[Crossref]

12. Mohan V, Shah SN, Joshi SR, Seshiah V, Sahay $B K$, Banerjee $S$, et al. Current status of management, control, complications and psychosocial aspects of patients with diabetes in India- Results from the Diab Care India 2011 Study. Indian J Endocrinol Metab. 2014;18(3)370-8.

DOI: $\quad 10.4103 / 2230-8210.129715$ [Crossref]

13. Goyal J, Kumar N, Sharma M, Raghav MS, Lal B, Bhatia PS. Factors affecting glycemic control among patients with type 2 diabetes at a tertiary health care center of western UP regiona cross-sectional study. Int J Health Sci Res. 2019;9(3)12-20.

[Crossref]

14. Alzaheb RA, Altemani $\mathrm{AH}$. The prevalence and determinants of poor glycemic control among adults with type 2 diabetes mellitus in Saudi Arabia. Diabetes Metab Syndr Obes. 2018; $11 ; 15-21$.

DOI: $10.2147 /$ DMSO. S156214 [Crossref]

15. Viana LV, Leitão CB, Kramer CK, Zucatti AT, Jezini DL, Felício J, et al. Poor glycaemic control in Brazilian patients with type 2 diabetes attending the public healthcare system- a crosssectional study. BMJ Open. 2013;3(9)e003336.

DOI: 10.1136/bmjopen-2013-003336 [Crossref]

16. Alramadan MJ, Magliano DJ, Almigbal TH, Batais MA, Afroz A, Alramadhan $\mathrm{HJ}$, et al. Glycaemic control for people with type 2 diabetes in Saudi Arabia - an urgent need for a review of management plan. BMC Endocr Disord. $2018 ; 18(1) 62$.

DOI: $\quad 10.1186 / s 12902-018-0292-9 \quad$ [Crossref]

17. Unnikrishnan R, Anjana RM, Deepa M, Pradeepa $R$, Joshi SR, Bhansali A, et al. Glycemic control among individuals with self-reported diabetes in India--the ICMR-INDIAB Study. Diabetes Technol Ther. 2014;16(9)596-603.

DOI: $10.1089 /$ dia.2014.0018 [Crossref] 